\title{
Lower Face Tumors of Non-Burkitt Origin in Malawi
}

\section{Sharma $\mathrm{K}^{1}$, Luiz $\mathrm{T}^{2}$, Rothe $\mathrm{C}^{3}$, Prin $\mathbf{M}^{4}$, Castner $\mathrm{T}^{4,5}$, Namboya $\mathrm{F}^{4,5}$ and Pollach $\mathbf{G}^{4,5 *}$}

${ }^{1}$ Dental Department, Queen Elizabeth Central Hospital, Ministry of Health, Germany

${ }^{2}$ Westpfalz-Klinikum Kaiserslautern, Germany

${ }^{3}$ Department of Internal Medicine, College of Medicine, Germany

${ }^{4}$ Department of Anaesthesia and Intensive Care, Queen Elizabeth Central Hospital, Germany

${ }^{5}$ Department of Anaesthesia and Intensive Care, College of Medicine, Germany

\section{Abstract \\ Background: Prevalence, demography and histology of non-Burkitt facial tumors is not known in Malawi}

Methods: A quantitative, prospective, monocentric study was conducted. 77 consecutive patients presenting to our dentistry department in Blantyre from 17.6.-16.5.2013 with lower face tumors. Data included age, gender, site of lesion, malignant features and histopathology.

Results: Mandibular tumors were found in 23 patients (29.9\%). Gingiva was affected in $11.7 \%$, palate in $8(10.4 \%)$ maxilla in $7(9.1 \%)$ and the tongue in $7(9.1 \%)$ patients. Twentyfive $(32.5 \%)$ of the lesions were malignant. Fourteen of them (56\%) were diagnosed as squamous cell carcinoma (SCC), three as Kaposi's (12\%). Other types of malignancies were rare. Malignant tumors were mostly found related to the palate $(32 \%)$ or to the tongue $(20 \%)$.

Most tumors were benign. Fibro-osseous lesions, cysts and ameloblastoma dominating. Patients with cemented fibroma (7 cases or $9.1 \%$ ), ameloblastoma ( 5 cases or $6.5 \%$ ) and cysts of odontogenic or non-odontogenic origin (13 cases or $16.9 \%$ ) were seen most often. $50.6 \%$ of our patients suffered from benign tumours. $36.4 \%$ had benign odontogenic tumours. $38.9 \%$ non-odontogenic tumors.

Frequency of malignancies for women between 50 and 70 was high (40\%).

Conclusion: Prevalence of ameloblastoma, frequency of malignancies for women between 50 and 70 and the significance of the palate as a site for malignant tumors differed from previous findings. Hopefully results will direct investment in maxillofacial surgery/anaesthesia in resource poor settings.

Keywords: Lower face tumors; Jaw tumors; Malawi; Anaesthesia and oromaxillofacial surgery; Non-Burkitt tumors in Malawi; Resource poor setting

\section{Introduction}

Many neoplastic conditions affect the oromaxillofacial region $[1,2]$, and these tumors most commonly affect the lower parts of the face [3]. Although the epidemiology of facial tumors is well known in high-income nations, the prevalence, demography, and histological origin of facial tumors in sub-Saharan Africa is not well known. The epidemiology of oromaxillofacial tumors in this region is likely very different from that of more developed regions because of the higher prevalence of Human Immunodeficiency/Acquired Immunodeficiency Syndrome (HIV/AIDS), Epstein- Barr Virus (EBV), and malnutrition with accompanying immune deficiencies. It is anecdotally known that patients in Malawi frequently present with advanced facial tumors which are not well known in the developed countries of the world. This constitutes a challenge for healthcare providers in sub-Saharan Africa because the airway management as well as the operative and postoperative management of late stage facial tumors is more difficult and morbid than that of early stage tumors [4]. Many of these challenges are compounded by the shortages of advanced airway equipment in this resource-limited region.

Retrospective studies of oromaxillofacial tumors in other areas of the world have demonstrated a geographic variation in the frequency, site and histology of the lesions. While data describing facial tumors is available from various developing countries including Nigeria [5], Ghana [6], Zimbabwe [7], Jordan [8], China [9], South Africa [10] and India [1] there are only few data from Eastern Africa. This study was designed in order to inform care of patients with oromaxillofacial tumors in sub-Saharan Africa and to compare the epidemiology in this region with reports from other parts of the world.
Malawi is one of the poorest countries in sub-Saharan Africa [11] with a life expectancy of approximately 54 years and a Gross National Income per capita of $\$ 320$. There are only 2 doctors and 38 nurses per 100,000 population [11]

The purpose of this study was to investigate the importance of maxillofacial tumors encountered in Malawi.

\section{Methods}

A quantitative, prospective, longitudinal, monocentric study was conducted on 77 consecutive patients presenting to the Department of Dentistry at the Queen Elizabeth Hospital in Blantyre (Q.E.C.H.) in Malawi over a two year period from June 17, 2011 to May 16, 2013 with oromaxillofacial tumors affecting the lower part of the face. The study was conducted in Q.E.C.H. A data collection tool has been designed and data were preoperatively collected. They included patient age, gender, site of lesion, malignant features and the histopathology of the lesion (from fine needle aspiration, biopsy, or surgical lesion excision).

Patients with Burkitt's lymphoma were excluded because this condition is better characterized in the literature and often systemic [12].

*Corresponding author: Gregor Pollach, Research Director, University of Malawi, Anaesthesia and Itensive Care, Blantyre, Malawi, Tel: 00491703470952 ; E-mail: gpollach@medcol.mw

Received April 09, 2018; Accepted May 14, 2018; Published May 18, 2018

Citation: Sharma K, Luiz T, Rothe C, Prin M, Castner T, et al. (2018) Lower Face Tumors of Non-Burkitt Origin in Malawi. Dentistry 8: 488. doi:10.4172/2161-1122.1000488

Copyright: ( 2018 Sharma K, et al. This is an open-access article distributed under the terms of the Creative Commons Attribution License, which permits unrestricted use, distribution, and reproduction in any medium, provided the original author and source are credited. 
All consecutive patients of the department of dentistry who did not suffer from Burkitt's lymphoma and who underwent a sampling procedure for pathology, were included in the enrollment. None was excluded. All collected data were kept in specific files and computed with Microsoft word. Obtained data were treated with privacy and confidentiality in the locker of the Head of Department.

The study did not interfere with patient management and it did not change procedures, patient care or therapy. No photos were taken, no original files were taken out of the operation theatre and all data were completely anonymized. No additional interventions were performed and the study did not pose any danger to the patient.

\section{Results}

Seventy-seven consecutive patients who presented with oromaxillofacial tumors were recruited and included in the study. The sample included $35(45.4 \%)$ men and $42(54.5 \%)$ women. 15 patients (19.5\%) were under 18 years with 9 boys (60\%) and 6 girls (40\%). Age was available for 73 patients. The mean age in patients with benign lesions was 31 years and in patients with malignancies 53.8 years (Figure 1).

Complete histopathological data were obtained for 71 patients (92.2\%).

Twenty-five (32.5\%) of the patients lesions presented were classified as malignant. Fourteen of them (56\%) were diagnosed as Squamous Cell Carcinoma (SCC), three with Kaposi's sarcoma (12\%). All other malignancies were seen only once or twice $(4 \%$ / 8\%) Of 25 patients presenting with malignancies 11 were male (44\%) and 14 female (56\%). No malignancies were found in children under 18 years.

From the patients suffering from a malignant tumor 10 were female in an age between 50 and 70 years ( $40 \%$ of all malignancies) and 4 male. Other decades accounted for both sexes only for 12 patients.

The 25 malignant tumors were most often found related to the palate in 8 patients $(32 \%)$ or to the tongue in 5 patients $(20 \%)$. This was followed by the lips (three patients or 12\%), the buccal region, the gingiva and the mandibula (each two patients or $8 \%$ ). The maxilla, the retromolar and the sublingual region showed only one patient suffering from a malignant tumor (4\%) (Table 1).

Tumors were predominantly found involving the mandible in 23

\section{Age in patients with malignancies}



Figure 1: Age in patients with malignancies. patients $(29.9 \%)$, the gingiva in nine $(11.7 \%)$, the palate in $8(10.4 \%)$, the maxilla in $7(9.1 \%)$ and the tongue in $7(9.1 \%)$ patients. Less commonly the buccal region was affected in 6 patients (7.8\%) the lips, the cheek and the parotid each in three patients (each 3.9\%) as well as the sublingual, the submandibular region with two patients each (each 2.6\%) and the retromolar region with one patient (1.3\%). In three patients the region was not absolutely clear where the specimen was taken from $(3.9 \%)$.

The majority of the tumors consisted of benign lesions such as fibroosseous lesions, cysts and ameloblastoma. Cemented fibroma occurred in $7(9.1 \%)$, other fibroma in $3(3.9 \%)$, ameloblastoma in $5(6.5 \%)$, pyogenic granuloma in $3(3.9 \%)$, fibroepithelial polyp in $3(3.9 \%)$ and various cysts in 10 (12.9\%) of our patients. Twenty-eight $(36.4 \%)$ had benign odontogenic tumours (including cysts). Thirty (38.9\%) had non-odontogenic tumors. 5 (17.9\%) of the benign odontogenic tumours were ameloblastoma. 24 other diagnosis were found only with one or two patients $(1.3 \% / 2.6 \%)$.

\section{Discussion}

This study confirms the findings of other regional investigations from Nigeria, Ghana, Cote D' Ivoire and Burkina Faso, that maxillofacial tumors affect the mandible and the lower face more often than the maxilla $[6,8,13,14]$. Informations on facial tumors is available from some countries in the developing world. We have data from Nigeria [5], Ghana [6], Zimbabwe [7], Jordan [8], China [9], South Africa [10] and India [1]. For wide parts of Eastern Africa and especially for Malawi this is not the case. For Uganda and Malawi there are two studies considering especially salivary gland tumors $[15,16]$ und a Malawian study on the association between Burkitt's Lymphoma and HIV, EBV and Malaria [12].

In order to compare studies of facial tumors, five criteria should be considered: The high prevalence of ameloblastoma in some countries [17], the existence of the so called "Noma-belt" in West-Africa with high prevalences of tumor-like infections in the lower face, the prevalence of Burkitt's Lymphoma in regions with mean temperatures over 16 degrees Celsius and below $1500 \mathrm{~m}$ of altitude and the prevalence of HIV, malnutrition and tropical conditions associated with facial tumours (e.g. onchocerciasis, keloids, leishmaniosis and lupus vulgaris) as well as the ability of patients suffering from albinism to reach medical treatment due to the high frequency of SCC in this population.

This study took place in a setting with an unknown prevalence of ameloblastoma, high HIV prevalence (15\%), relatively good access for the albino population to health care and in a country outside the Nomabelt with a low prevalence of onchocerciasis, existing lupus vulgaris and no leishmaniosis. To the best of our knowledge this is the first time in literature that demographic details of non-Burkitt-related maxillofacial tumors are discussed for Malawi.

The most common benign lesions of the lower face were cemented fibromas and the ameloblastoma. Nevertheless benign cysts were twice as common as ameloblastoma. The incidence for ameloblastoma amongst Africans is more than double that for Caucasians [18] and around $18 \%$ of odontogenic tumors are ameloblastoma [19]. In a South-African study [10] Ameloblastoma was the most frequent benign tumour (43\%) and it was the most common odontogenic tumor in the first 2 decades of life. Similar results we find in studies from Nigeria [13,20], Egypt [21], Brazil [22], China [9], Sri Lanka [23], and Turkey [24], whereas data from two arguably more developed American countries (California [25] and Argentina [26]) show odontoma as the most common one. HIV rate and demographics are important for the 
Citation: Sharma K, Luiz T, Rothe C, Prin M, Castner T, et al. (2018) Lower Face tumors of Non-Burkitt Origin in Malawi. Dentistry 8: 488. doi:10.4172/2161-1122.1000488

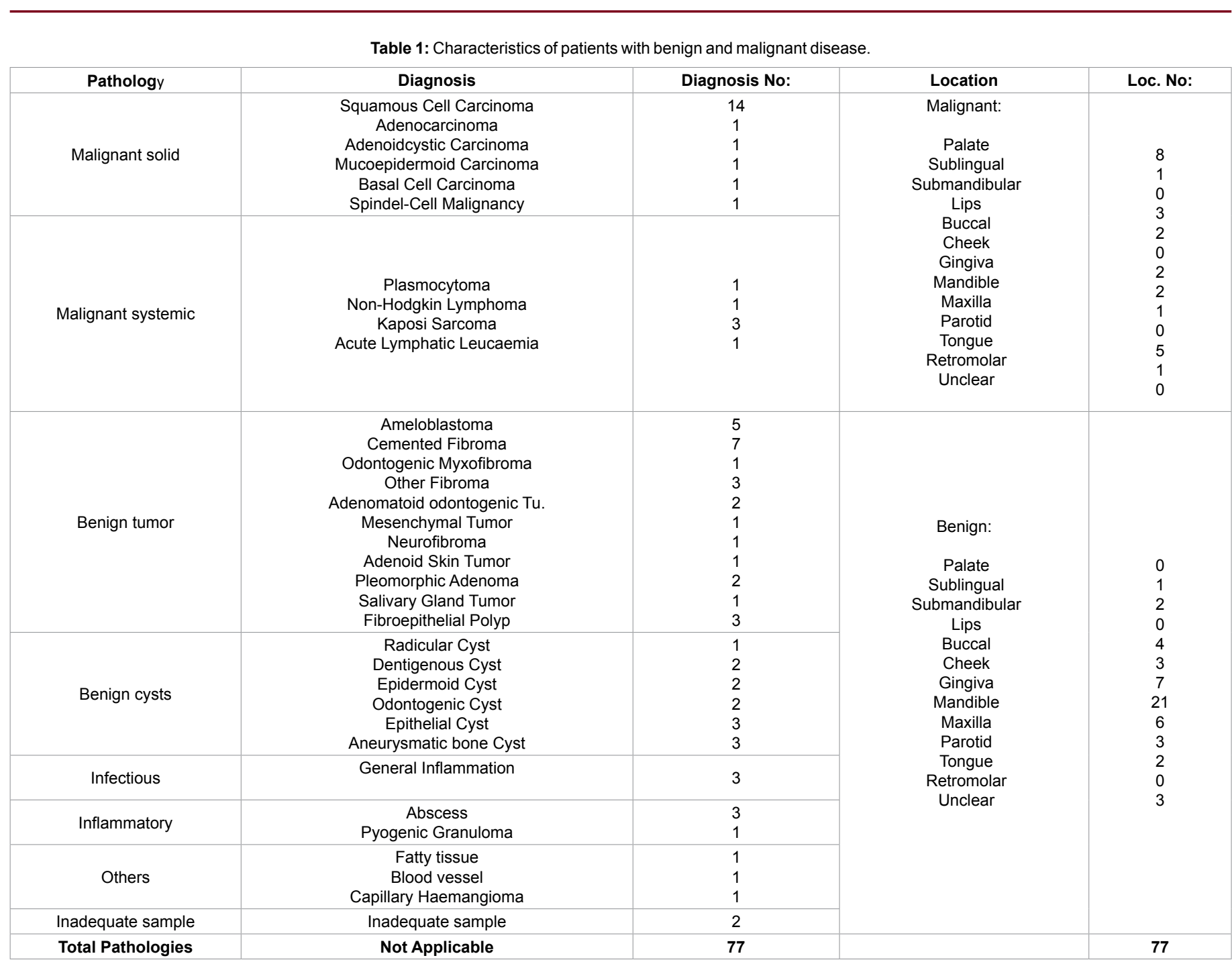

prevalence of tumors. Both factors are similar for Malawi and South Africa. This study showed that $17.8 \%$ of the benign odontogenic tumors were ameloblastomas.

Tumors of odontogenic origin are lesions derived either from epithelial elements like the ameloblastoma or mesenchymal parts of the tooth forming apparatus. Because we have only data from our institution and our catchment area is impossible to assess correctly we cannot deliver exact data for the presumed incidences of ameloblastoma in Malawi. When we assume, that we serve around a third of the population of Malawi and we further assume, that all other institutions in our catchment area together see additionally the same number of patients a year without referring them to us and we find a population of around 15 million Malawians, than we would calculate an incidence (male and female patients together) of 1 patient per million per year. This is near the published incidences [18].

This study population had a high prevalence of cemented fibroma, a relatively rare tumor.

The most common malignant tumor was the Squamous Cell Carcinoma (SCC), which accounted for more than $56 \%$ of the malignant tumors. SCC is known to be the most common malignancy in the oral cavity [4] and accounts for upto $90 \%$ of reported oral malignant tumors. This is true even in regions, where betel nut chewing or inverse smoking is not common practice. In Malawi these practices are not widespread, but at least the older generation in the villages is known to chew tobacco. The observed SCC prevalence in this study (56\%) is relatively close to the $73.1 \%$ found in neighboring Zimbabwe [7]. The palate was an uncommonly highly affected site of the malignant tumors.

The second most common malign tumor in our cohort was Kaposi's Sarcoma (KS). We did not test all study patients for HIV, but given that the national HIV prevalence in Malawi is $15 \%$ this is unsurprising. With success in antiretroviral treatment regimens in high-income nations, Kaposi's Sarcoma is no longer frequently discussed in public health strategies, but the prevalence of KS in our sample may indicate a need for more vigilant surveillance amongst immune compromised patients in this region.

We found a high percentage (40\%) of our patients suffering from a malignant tumor to be female and in an age between 50 and 70 . Considering the life expectancy in Malawi (around 45 years) this is a gross overrepresentation, we cannot explain.

This study had several limitations. Some histopathological results were not satisfactory secondary to inadequate sample collection or inadequate history. The variety of diagnoses was large (32 diagnosis in 77 patients or $0.42 /$ patient) in comparison to other studies, \{Ajagbe et al. (0.12), Mamabolo et al. (0.02), Ahmet-Ercan et al. (>0.07) or Parkins 
Citation: Sharma K, Luiz T, Rothe C, Prin M, Castner T, et al. (2018) Lower Face tumors of Non-Burkitt Origin in Malawi. Dentistry 8: 488. doi:10.4172/2161-1122.1000488

et al. $(0.06)[5,6,10,24]\}$. This may be a feature of our population or could be secondary to poor quality control in histopathology. The number of participants included in our study was comparable to many other similar studies like the ones of Ajagbe et al., Mamabolo et al., Ahmet-Ercan et al., or Parkins et al. [5,6,10,24].

We did not see very much children in our cohort of the dentistry department. Probably this is because we have an extremely active department of paediatric surgery in the hospital, which does treat most patient who first present to them in their own department. Moreover nomenclature in these types of tumors is not without challenges. Mamabolo found in a study from 2011 [10] that the most recent World Health Organization Classification of Odontogenic Tumours, which was based on the germ cell layer of origin, differs much from the previous 1992 classification and that only 3 studies in recent literature are based on the new classification [27].

This study may be extremely valuable to inform the care of oromaxillofacial tumor patients in the extremely limited resource setting of Malawi. Even small tumors can influence the ability to secure the airway. Very late presentations with the consequences of a severe disfigurement and aggressive surgery with a long and complicated stay in the intensive care unit are further consequences. Patients with facial tumors should always be considered by the most experienced multidisciplinary team to establish the earliest diagnosis and to proceed with safe oncological and surgical care. This may be very difficult in countries with limited medical resources.

\section{Conclusion}

In this study, the prevalence of ameloblastoma, the frequency of malignancies for women between 50 and 70 , and the significance of the palate as a site for malignant tumors differed from previous findings. We hope that our demographic and histological results will enable improved preoperative planning in anaesthesia, support decision making in maxillofacial surgery and improve financial investments in both departments.

\section{Declarations and Disclosures}

The authors declare that they have no conflict of interest and that the study did not receive any funding.

\section{Acknowledgements}

We thank all our patients, nurses, clinical officers and administration clerks, who made the work possible

\section{References}

1. Mullapudi SV, Putcha UK, Boindala S (2011) Odontogenic tumors and giant cell lesions of jaws- a nine year study. World J Surg Oncol 9: 68.

2. Theodorou DJ, Theodorou SJ, Sartoris DJ (2003) Primary non-odontogenic tumors of the jawbones: an overview of essential radiographic findings. Clin Imaging 27: 59-70.

3. Harrison D, Lund VJ (1995) Tumours of the Upper Jaw. Edinburgh, Churchill Livingstone pp.1-50.

4. Peter N, Venter T. Jaw Tumors. In: Carter LL (Ed.) (2013) Principles-ofReconstructive-Surgery-in-Africa, Pan African Academy of Christian Surgeons, A PAACS publication Version 24 July 2013.

5. Ajagbe HA, Daramola JO (1982) Primary Tumors of the Jaw in Nigerian Children. J Natl Med Assoc 74: 157-161.
6. Parkins GEA, Armah G, Ampofo P (2007) Tumours and tumour-like lesions of the lower face at Korle Bu Teaching Hospital, Ghana- an eight year study. World J Surg Oncol 5: 48

7. Chidzonga MM (2006) Oral malignant neoplasia: a survey of 428 cases in two Zimbabwean hospitals. Oral Oncology 42: 177-183.

8. Al-Khateeb T, Hamasha AA, Almasri NM (2003) Oral and Maxillofacial tumours in North Jordanian children and adolescent: a retrospective analysis over 10 years. Int J Oral Maxillofac Surg 32: 78-83.

9. Jing W, Xuan M, Lin Y, Wu L, Liu L, et al. (2007) Odontogenic tumours: a retrospective study of 1642 cases in a Chinese population. Int J Oral Maxillofac Surg 36: 20-25.

10. Mamabolo M, Noffke C, Raubenheimer E (2011) Odontogenic tumours manifesting in the first two decades of life in a rural African population sample: a 26 year retrospective analysis. Dentomaxillofac Radiol 40:331-337.

11. http://data.worldbank.org

12. Mutalima N, Molyneux E, Jaffe H, Kamiza S, Borgstein B, et al. (2008) Associations between Burkitt Lymphoma among Children in Malawi and Infection with HIV, EBV and Malaria: Results from a Case-Control Study. PLoS One.

13. Ajayi OF, Ladeinde AL, Adeyemo WL, Ogunlewe MO (2004) Odontogenic tumors in Nigerian children and adolescents-a retrospective study of 92 cases. World J Surg Oncol 2: 39-48.

14. Adebayo ET, Ajike SO, Adekeye EO (2001) Tumours and tumour-like lesions of the oral and perioral structures of Nigerian children. Int J Oral Maxillofac Surg 30: 205-208.

15. Davies JNP, Dodge OP, Burkitt DP (1964) Salivary gland tumors in Uganda Cancer 17: 1310-1322.

16. Thomas KM, Hutt MSR, Borgstein J (1980) Salivary gland tumors in Malawi Cancer 46: 2328-2334.

17. Palmer PES, Reeder MM (2001) The imaging of Tropical Diseases Springer Berlin 2: 600-671.

18. Shear M, Singh S (1978) Age-standardized incidence rates of ameloblastoma and dentigerous cyst on the Witwatersrand, South Africa. Community Dent Oral Epidemiol 6(4): 195-199.

19. Jonathan Gordo (2008) Clinical Quiz: Painless Mass. Appl Radiol Online 3(8).

20. Arotiba GT, Ladeinde AL, Arotiba JT, Ajike SO, Ugboko VI, et al. (2005) Ameloblastoma in Nigerian children and adolescents: a review of 79 cases. $J$ Oral \& Maxillo fac Surg 63: 747-751.

21. Tawfik MA, Zyada MM (2010) Odontogenic tumors in Dakahlia, Egypt: analysis of 82 cases. Oral Surg Oral Med Oral Pathol Oral Radiol Endod 109: e67-e73.

22. Fernandes AM, Duarte ECB, Pimenta FJ, Souza LN, Santos VR, et al. (2005) Odontogenic tumors: A study of 340 cases in a Brazilian population. J Oral Pathol Med 34: 583-587.

23. Okada H, Yamamoto H, Tilakaratne WM (2007) Odontogenic tumors in Sri Lanka: Analysis of 226 cases. J Oral Maxillo fac Surg 65: 875-882.

24. Ahmet-Ercan S, Nazlım S, Meryem E, Denız K, Yasa Y (2015) Odontogenic tumors: A collaborative study of 218 cases diagnosed over 12 years and comprehensive review of the literature. Med Oral Patol Oral Cir Bucal 20(14): e34-e44.

25. Buchner A, Merrell PW, Carpenter WM (2006) Relative frequency of centra odontogenic tumors: A study of 1088 cases from northern California and comparisons from other parts of the world. J Oral Maxillofac Surg 64: 13431352.

26. Guerris M, Piloni MJ, Kezler A (2007) Odontogenic tumors in children and adolescence. A 15-year retrospective study in Argentina. Med Oral Patol Oral Cir Bucal 12: E180-185.

27. World Health Organisation: Country cooperation strategy. 